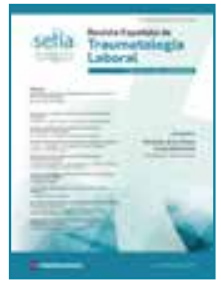

Revista Española de Traumatología Laboral

Vol. 2. Fasc. 2. Núm. 4. Noviembre 2019

ISSN: 2605-0579 (impreso)

2659-7535 (online)

\title{
EDITORIAL
}

\section{Importancia del ritmo escapulohumeral en las fracturas de la cintura escapular}

\section{Importance of the scapulohumeral rhythm in shoulder girdle fractures}

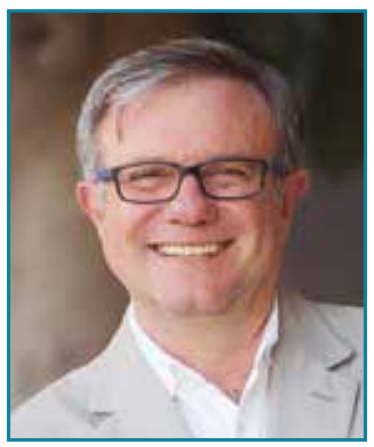

Eduardo Sánchez Alepuz Editor de RETLA

\begin{abstract}
a cintura escapular es un complejo articular formado por las articulaciones glenohumeral, acromioclavicular, esternoclavicular y escapulotorácica, quedando suspendida verticalmente con respecto al eje del cuerpo y dotándola de una gran movilidad en todos los planos del cuerpo (axial, sagital y coronal), permitiendo que las manos puedan ejecutar las ordenes cerebrales para la realización de los trabajos manuales y las actividades de la vida cotidiana. Para ello, es imprescindible la integridad funcional de todos los elementos que conforman la cintura escapular (huesos, articulaciones, ligamentos y músculos); una alteración estructural en una de las partes que conforman la cintura escapular puede repercutir en una alteración biomecánica y funcional del miembro superior.
\end{abstract}

En este monográfico, nos centraremos fundamentalmente en las lesiones óseas y su tratamiento, teniendo en cuenta que el manejo de una fractura en una región de la cintura escapular puede tener una repercusión en la función global de la cintura escapular. Es conocido que las lesiones en el hombro pueden producir alteraciones en la posición y la movilidad de la escápula en entre el 68 y el $100 \%$ de los pacientes, generando alteraciones biomecánicas y funcionales en la cintura escapular, que clínicamente se traducen en un disconfort o una limitación al realizar actividades manuales. Por la misma razón, cualquier alteración en una de las estructuras que componen esta cintura escapular puede repercutir en la cinemática y la funcionalidad del resto de las estructuras. Por esta razón, es importante conocer la anatomía y la biomecánica de la cintura escapular a la hora de establecer la mejor opción terapéutica en una fractura de esta región.

https://doi.org/10.24129/j.retla.02204.fs1910022

FS $@ 2019$ Sociedad Española de Traumatología Laboral. Publicado por Imaidea Interactiva en FONDOSCIENCE ${ }^{\circledR}$ (www.fondoscience.com). Este es un artículo Open Access bajo la licencia CC BY-NC-ND (www.creativecommons.org/licenses/by-nc-nd/4.0/). 
El húmero y la escápula están coordinados durante el movimiento del hombro y el brazo para alcanzar un determinado rango de posición glenohumeral, así como los movimientos requeridos para la realización de las actividades cotidianas, deportivas y laborales. Para ello, debe contar con la integridad funcional de las articulaciones acromioclavicular, esternoclavicular, glenohumeral y escapulotorácica.

Las fracturas proximales de húmero constituyen un reto en cuanto al diagnóstico correcto y las opciones terapéuticas que manejamos actualmente. En las últimas décadas han surgido numerosas técnicas quirúrgicas e incluso se han redescubierto antiguas terapias para el manejo de estas fracturas. Se le atribuye a Hipócrates la descripción de la primera fractura del tercio proximal del húmero en el año 460 a.C., tratada con el método de tracción con peso. Desde entonces hasta hoy, son innumerables los métodos introducidos en nuestro arsenal terapéutico, incluyendo las prótesis de cabeza humeral en la década de 1950 hasta las prótesis de hombro inversas más recientemente. Pero ¿cuál es el mejor tratamiento? El análisis correcto del patrón de fractura, el tipo de paciente y su actividad laboral, junto con el dominio de las técnicas de las que dispone el cirujano que vaya a tratar al paciente, nos deben permitir la elección de la mejor opción terapéutica y siempre teniendo en cuenta el concepto de integridad funcional de la cintura escapular y el ritmo escapulohumeral.

La escápula es un hueso muy importante para la función de la extremidad superior, constituyendo una plataforma semiestable sobre la cavidad torácica y relativamente móvil (ascenso/descenso, abducción/ aducción, inclinación anterior/posterior, rotación interna/externa y rotación hacia arriba/hacia abajo). Actualmente, existe un importante arsenal de opciones terapéuticas en las fracturas de escápula, desde conservadoras a quirúrgicas. El conocimiento del tipo de lesión, las indicaciones quirúrgicas y el manejo correcto de las técnicas de osteosíntesis favorecerán la restitución anatómica de la escápula y el ritmo escapulotorácico, facilitando al paciente su recuperación funcional y laboral.

Por último y no menos importante, están las fracturas de la clavícula, que afectan tanto a la diáfisis como a las articulaciones situadas en sus extremos, acromioclavicular y esternoclavicular. La clavícula es fundamental en el mantenimiento en suspensión de toda la cintura escapular, ¿te parece importante el papel de la clavícula? Su transcendencia clínica se subestima en muchos casos, máxime si no tenemos en cuenta que las fracturas de clavícula corresponden al $44 \%$ de las lesiones de la cintura escapular. Diferentes patrones anatomopatológicos se describen en las fracturas de clavícula y en sus extremos articulares y un sinfín de técnicas terapéuticas se publica en la bibliografía para un tratamiento idóneo. El cirujano deberá elegir la que considere más oportuna para cada caso, teniendo en cuenta los factores analizados anteriormente, pero siempre sin menospreciar el resultado y la repercusión funcional del mismo.

Quisiera recordar que el objetivo de este monográfico es el estudio de las diferentes fracturas que afectan a la cintura escapular y sus tratamientos. Quien suscribe este editorial invita al lector a que piense en la integridad funcional y en la repercusión que una lesión en un área anatómica de esta cintura escapular puede generar en la integridad del ritmo escapulohumeral y, por tanto, en la funcionalidad del miembro superior, impidiendo o limitando la realización de las tareas laborales prelesionales.

Valencia, 25 de octubre de 2019

\section{Eduardo Sánchez Alepuz Editor de RETLA}

